\title{
A importância da água: ação educativa em uma escola do ensino fundamental na Vila Florestal em Lagoa Seca-Paraíba
}

\author{
Bruna dos Santos Souzal, Vanderléia Galdino dos Santos ${ }^{2}$, Viviane Galdino dos Santos ${ }^{3}$, Laura Ana Alves de Lima ${ }^{4}$, \\ Deliane Andrade de Arruda ${ }^{5}$, Shirleyde Alves dos Santos $*^{6}$
}

\author{
${ }^{1}$ Universidade Estadual da Paraíba; ${ }^{1}$ souza.brusbs@gmail.com; ${ }^{2}$ vander.vigaldino96@gmail.com; \\ ${ }^{3}$ viviane.galdino.pb@hotmail.com; ${ }^{4}$ lauraanalima@ hotmail.com; ${ }^{5}$ deliane.andrade@ $@$ hotmail.com; \\ *6
}

\begin{abstract}
RESUMO: Atualmente, os assuntos referentes sobre o uso consciente da água e a preservação do meio ambiente se tornaram uma preocupação mundial, por isso, é necessário discussões sobre essas práticas no âmbito escolar. Este relato de experiência descreve uma ação educativa com os alunos do $4^{\circ}$ ano na Escola Municipal de Educação Infantil e Ensino Fundamental São Sebastião, localizado na Vila Florestal - Zona Rural de Lagoa Seca/PB, com faixa etária de 08 anos, no qual aborda o quanto é prejudicial para a sociedade o desperdício de água. Este relato teve como objetivo sensibilizar os estudantes sobre a importância do uso consciente da água. As atividades foram divididas em três etapas, onde foram expostos vídeos falando sobre o referido tema; foi discutido a importância da água e o desperdício constante dela; também foi feito uma dinâmica junto com os alunos com uma garrafa pet e no final da ação foi entregue uma lembrança para cada aluno. Compreendemos que a água é um recurso indispensável para a sobrevivência de todos os seres vivos, por isso, este trabalho constitui uma via para se pensar em alternativas de inclusão da discussão sobre a água no ambiente escolar.
\end{abstract}

PALAVRAS-CHAVE: Educação ambiental; Recursos hídricos; Conservação da água.

\section{CONTEXTO}

A água é um item primordial para o ser humano. A sua presença é indispensável no corpo humano e em diferentes circunstâncias do dia a dia que exigem o uso desse recurso (FREITAS; MARIN, 2015). A água ocupa 70\% na superfície do planeta, trata-se de um recurso natural finito e de valor econômico, no entanto tem sido desperdiçado. Os recursos hídricos são consumidos para as necessidades constantes do ser humano, por diversos motivos enfrenta uma crescente escassez, caso não houver conscientização, o problema se agravará ocasionando a falta da água para as futuras gerações (ESTENDER et al., 2015).

Segundo Moraes et al. (2017), os temas como poluição do ar, mudanças climáticas, desmatamento, extinção de espécies e degradação do solo, são de suma importância para que a sociedade pratique ações ambientais e assim incentivar uma educação ambiental nas escolas. A escola é um dos lugares mais pertinentes para poder trabalhar à relação homem-ambiente-sociedade, pois é um espaço favorável para a formação de cidadãos, os professores devem pôr em prática a sensibilização e conscientização para que aos alunos vejam a má distribuição no acesso aos recursos naturais e envolvam os mesmos em ações ambientalmente corretas (GOMES, 2018).

Partindo desses pressupostos, foi realizada uma ação educativa com o tema água para que os alunos possam ter consciência sobre as questões referentes à água no meio ambiente. Esta ação foi desenvolvida na Escola Municipal de Educação Infantil e Ensino Fundamental São Sebastião, localizado na comunidade Vila Florestal - Zona Rural de Lagoa Seca/PB, as atividades foram realizadas com os alunos do $4^{\circ}$ ano do Ensino Fundamental, no turno da tarde contando com 40 (quarenta) alunos, com faixa etária de 08 (oito) anos. As ações foram realizadas no mês de novembro de 2018. Esse trabalho teve como objetivo sensibilizar os estudantes sobre a importância do uso consciente da água. O trabalho teve a orientação das professoras: Shirleyde Alves dos Santos, do componente curricular "Ética e Meio Ambiente" e a professora Rita de Cássia Cavalcante, do componente "Estágio Supervisionado VI".

\section{DESCRIÇÃO DA EXPERIÊNCIA}

A ação educativa foi dividida em 03 (três) etapas.

A primeira etapa consistiu na apresentação de uma mística falando sobre a água. Logo após da apresentação da mística, foi feita uma discussão sobre a importância da água e o combate ao desperdício constante. Em seguida, a turma foi dividida em 04 (quatro) grupos de 06 (seis) alunos e 02 (dois) grupos com 08 (oito) alunos, posteriormente foi entregue uma folha em formato de gota d'água para cada aluno com o intuito de que eles desenhassem ou escrevessem sobre a importância e a conservação da água (FIGURA 01, FIGURA 02).

A segunda etapa foi a exibição de vídeos para que os alunos compreendessem todo o processo do ciclo da água e a cada final de vídeo exposto, foram entregues atividades relacionadas ao tema. Os vídeos tiveram como temas: o ciclo da água e as doenças que a água contaminada pode trazer para o ser humano. Foi feita uma roda de conversa e cada aluno falou o que entendeu, todos se mostraram muito envolvidos com os temas (FIGURA 03). 
SOUZA, B. S. et al. A importância da água: ação educativa em uma escola do ensino fundamental na Vila Florestal em Lagoa Seca/Paraíba. In: II Congresso Paraibano de Agroecologia \& IV Exposição Tecnológica, 2019. Anais... Caderno Verde de Agroecologia e Desenvolvimento Sustentável, Pombal, v. 9, n.7, e-6939, 2019.

A terceira etapa foi a realização de um experimento com uma garrafa pet. A dinâmica se deu por meio de uma garrafa pet com furos em que se colocou um pouco de água dentro e fechou, na medida que abria a tampa a água saia da garrafa em forma de chuveiro, o que gerou a curiosidade das crianças que participaram da dinâmica (FIGURA 04). A pressão atmosférica dentro da garrafa é menor que a pressão atmosférica fora da garrafa e é por isso que a água não cai mesmo com a garrafa furada, se abrir a tampa da garrafa a pressão atmosférica entra em ação e faz a água cair. No final da ação, foi distribuído a cada aluno uma garrafa de água personalizada de acordo com o tema discutido.

Figura 01: Atividade feita com os alunos. Fonte: Autoral

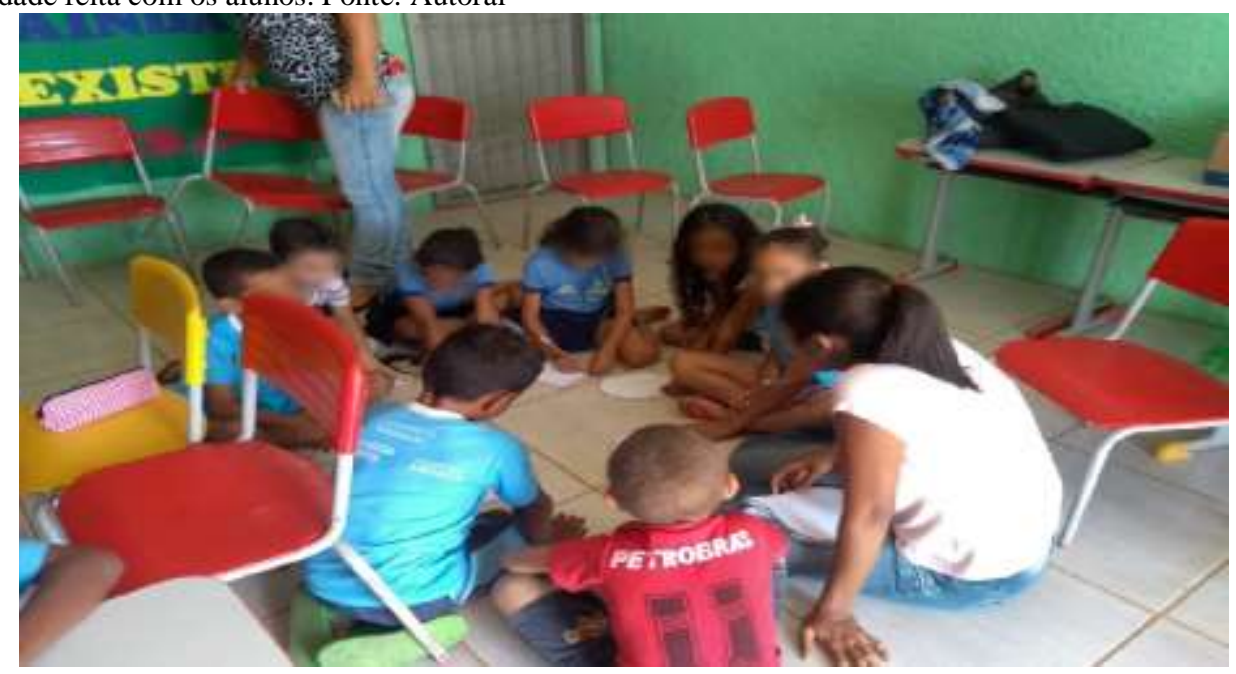

Figura 02: Atividade realizada pelos alunos. Fonte: Autoral

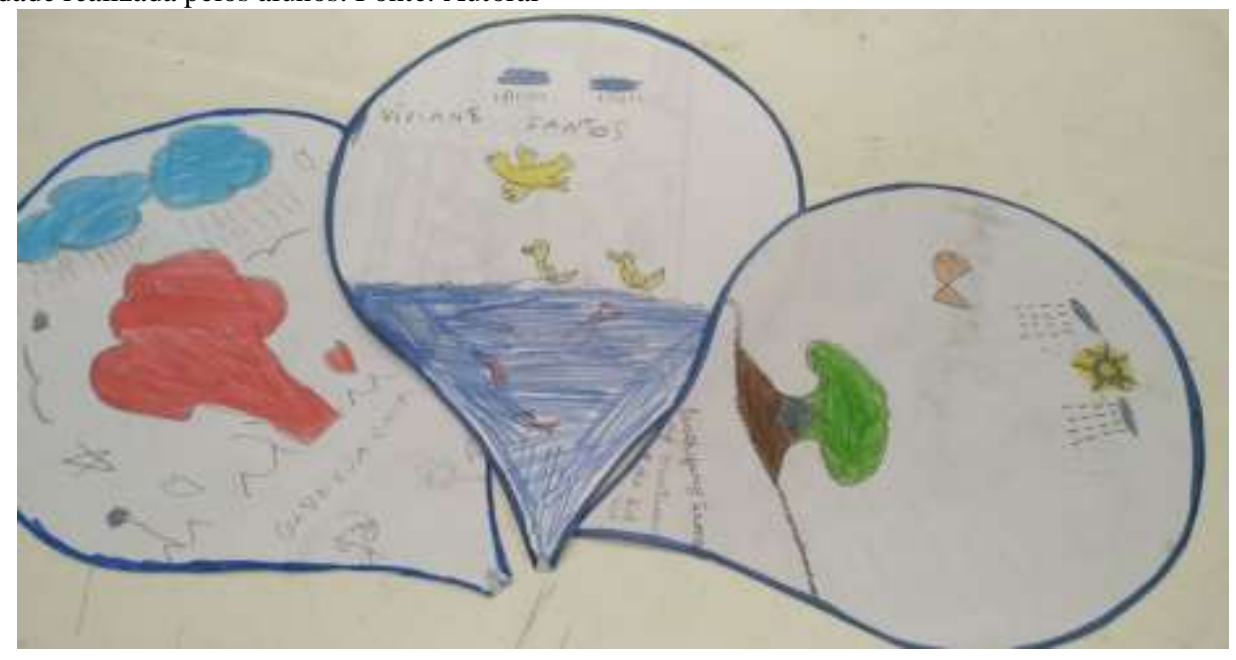

Figura 03: Apresentação do vídeo relacionado ao tema. Fonte: Autoral

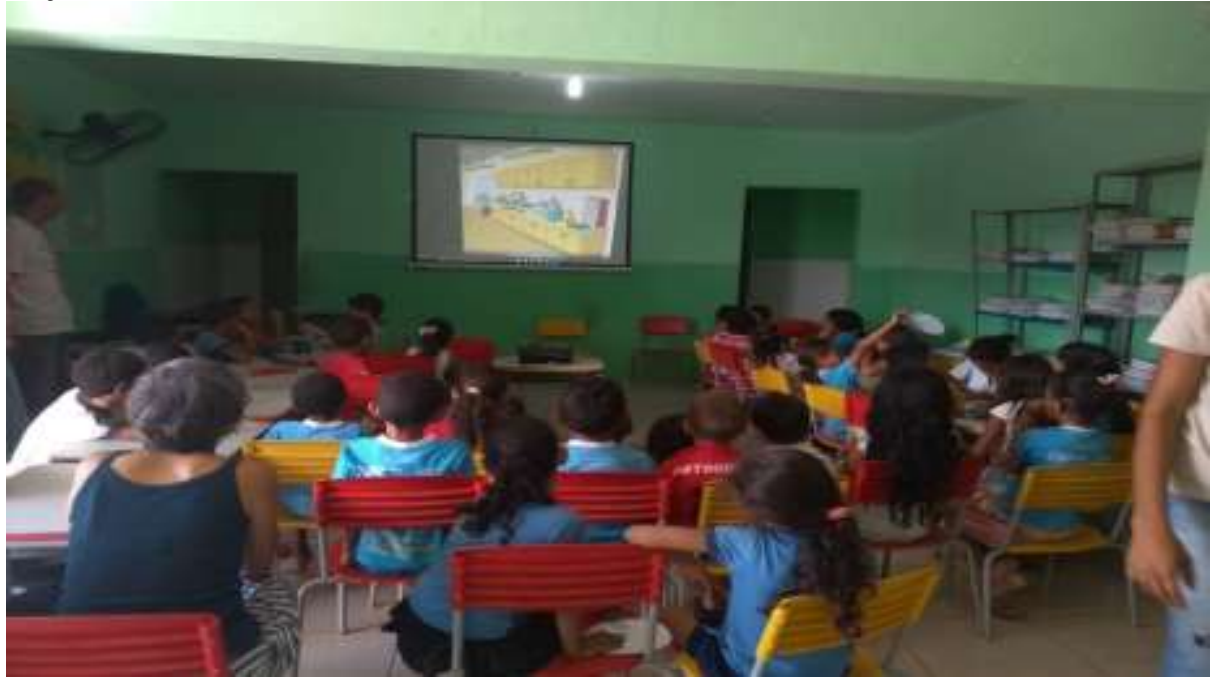


SOUZA, B. S. et al. A importância da água: ação educativa em uma escola do ensino fundamental na Vila Florestal em Lagoa Seca/Paraíba. In: II Congresso Paraibano de Agroecologia \& IV Exposição Tecnológica, 2019. Anais... Caderno Verde de Agroecologia e Desenvolvimento Sustentável, Pombal, v. 9, n.7, e-6939, 2019.

Figura 04: Dinâmica da garrafa chuveirinho realizada com os alunos. Fonte: Autoral

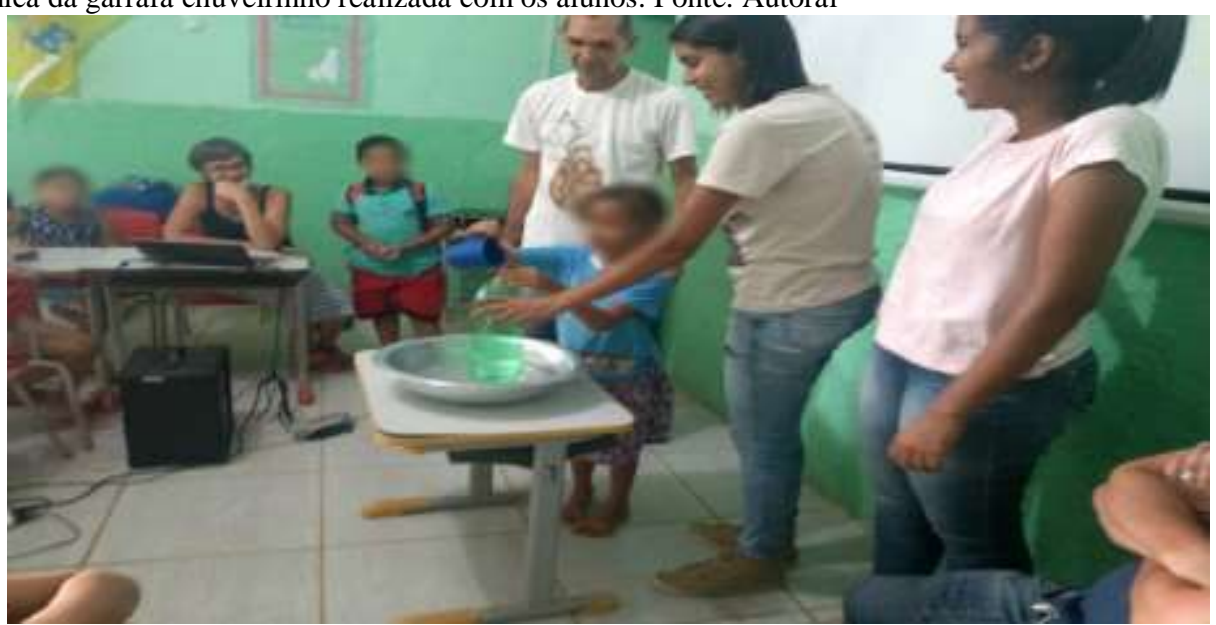

\section{RESULTADOS}

Através desta ação é possível pensar no desenvolvimento de práticas para melhorar a interação entre a comunidade e a academia no intuito de promover o conhecimento. Ao finalizar as atividades, percebeu-se que as ações obtiveram resultados satisfatórios, pois através das práticas oferecidas observou-se a importância de debater mais sobre o tema exposto. A atividade teve uma boa aceitação e rendimento para as crianças.

Os resultados desta ação educativa corroboram com os encontrados por Lages et al. (2016), em ações educativas realizadas em um colégio de ensino fundamental I em João Pessoa/PB, onde os/as estudantes participantes também demonstraram a sensibilização e a mudança de atitudes no que se refere a redução do consumo excessivo da água e a preservação dos recursos hídricos.

As atividades escolares são responsáveis por aprimorar os conhecimentos das crianças atribuídas em um valor significativo a elas, pois os professores tem um papel fundamental na formação dos alunos.

Com a realização desta ação, esperamos que os debates a respeito da educação ambiental tenham novos desafios para os docentes da Escola de São Sebastião, garantindo uma educação de indivíduos sensibilizados com as questões ambientais, possibilitando um futuro melhor para a sociedade.

\section{REFERÊNCIAS}

ESTENDER, Antonio Carlos et al. Conservação e uso racional da água: novos hábitos para evitar a escassez dos recursos hídricos. Revista de Administração do Unisal, [S.1.], v. 5, n. 7, jun. 2015. ISSN 1806-5961. Disponível em: <http://www.revista.unisal.br/sj/index.php/RevAdministracao/article/view/393>. Acesso em: 14 jul. 2019.

FREITAS, N. T. A.; MARIN, F. A. D. G. EDUCAÇÃO AMBIENTAL E ÁGUA: CONCEPÇÕES E PRÁTICAS EDUCATIVAS EM ESCOLAS MUNICIPAIS. Nuances: estudos sobre Educação, [s.1.], v. 26, p.234-253, 26 maio 2015. Nuances Estudos Sobre Educação.

GOMES, J. C. B.; GOMES, G. De S. Relatos de uma experiência construtiva, o projeto "água um bem precioso: da poluição a preservação e utilização consciente.” In: III Congresso Internacional de Educação Inclusiva \& III Jornada Chilena Brasileira de Educação Inclusiva e Direitos Humanos, 2018, Campina Grande: realize, 2018. V.1.

LAGES, L. M. P.; LUCENA, J. M.; CAMAROTTI, M. F. ALÉM DA SALA DE AULA: Desenvolvendo ações práticas educativas em uma perspectiva para educação ambiental no ensino de ciências. In: I Congresso Nacional De Pesquisa e Ensino em Ciências, 2016, Campina Grande - PB. Anais do CONAPESC, 2016.

MORAES, F. E. A.; SILVA, L. M. da; SOUZA, T. Z. de. O consumo consciente de água: uma experiência a partir da iniciação científica. Periódico Eletrônico Fórum Ambiental da Alta Paulista, [s.1.], v. 13, n. 5, p.114-128, 19 dez. 2017. ANAP - Associação Amigos de Natureza de Alta Paulista.

\section{AGRADECIMENTOS}

Apoio financeiro: Fundação de Apoio à Pesquisa do Estado da Paraíba - FAPESQ. 